\title{
Synthesis and Fabrication of Silica Based Superhydrophobic
}

\section{Surfaces}

\section{El-hoshoudy AN1,2* \\ 1Production department, Egyptian Petroleum Research Institute, Egypt \\ ${ }^{2}$ Petroleum Engineering department, Faculty of Engineering, British University in Egypt, Egypt}

*Corresponding author: Abdelaziz El-hoshoudy, Production department, Egyptian

\section{ЕВООК}

Volume 3 Issue 1

Received Date: February 07, 2019

Published Date: February 27, 2019

DOI: $10.23880 /$ ppej-16000181

Petroleum Research Institute, Egypt, Tel: 1143776927; Email: azizchemist@yahoo.com

\section{Abstract}

Superhydrophobic surfaces with very high water contact angle $>150^{\circ}$ and very low roll-off angle have received more attentions due to their huge potential in environment, energy and biomedical applications. It is now well known that superhydrophobicity arises from a combination of low surface free energy and surface roughness. Superhydrophobic coatings were fabricated by spraying the silica hybrid emulsion on clean glass substrates. Then, the effects of the emulsion dosage and the mole ratio of silica on the coating performance were analyzed. Finally, the formation mechanism of the hybrid coating was discussed, and the self-cleaning properties of the superhydrophobic and hydrophobic coating tilting at the same angle were also compared. The results show that the hydrophobic silica nanoparticles can form rough micro/nanostructure on the coating surface, since they act as a solid plasticizer capable of enhancing the surface properties. This work is divided in the following sections

1. Introduction

2. Mechanism of the sol-gel process

3. Literature review

4. Conclusion

Keywords: Surface coating; Silica coating; Hydrophobicity

\section{Introduction}

Learning from nature is an important source of new techniques and advanced materials. A typical example of this is the creation of superhydrophobic surfaces by bionic copying of the microstructure of lotus leaves [1-6]. On these superhydrophobic surfaces, water droplets remain nearly spherical and easily roll off, removing dirt in their path [7] without wetting the surface $[8,9]$. The superhydrophobic behavior of lotus leaves, known as the lotus leaf effect or self-cleaning effect, resulted from the hierarchical rough structure, as well as the wax layer present on the leaf surface $[10,11]$. It has been well established that the wettability of a solid surface is 


\section{Petroleum \& Petrochemical Engineering Journal}

governed by both the surface chemical composition and the surface geometrical microstructures [12-16]. Superhydrophobic surfaces are defined as surfaces with water contact angle greater than $150^{\circ}[17,18]$ and sliding angle below $10^{\circ}[19,20]$. Superhydrophobicity arises from a combination of low surface free energy and surface roughness [21]. There are two general methods for fabrication of artificial superhydrophobic surfaces: roughening of hydrophobic surfaces [22-24] and decrease the surface energy of a rough surface by chemically bonding low surface-energy species to the surface (i.e. modifying the rough surfaces with low surface free energy materials) [24-31]. In other words, to fabricate a surface with a water contact angle larger than $150^{\circ}$, two key factors must be considered; 1 ) When the surface energy is lowered, the hydrophobicity is enhanced. However, even the material with the lowest surface energy gives a water contact angle of only around $120^{\circ}$ [32]; 2) very large contact angle and a superhydrophobic behavior can be determined only if low surface energy and elevated roughness are simultaneously present. The superhydrophobic behavior of a solid surface depends on the synergistic contribution of surface chemical composition (i.e. low energy materials) and unique morphologies (e.g. micro-nano hierarchical structure, a porous nanostructure) [33,34]. Superhydrophobic surfaces with high water contact angle acquire increased attentions due to their huge potential application in environment, energy and biomedical fields $[13,35,36]$, oilwater separation [37], self-cleaning [38] or water directional flowing [39], anticorrosion, anti-fouling, antifrost/anti-icing and antimicrobial [28,33,40,41], electronic and optical devices[42], photonic materials[43], oil water separation [44,45], drag reduction [46-48], antiicing [49] and templates for fabricating bio and chemical sensors, and microfluidics [24,50,51]. Moreover, combining the synthesis of a superhydrophobic structure with materials that are responsive to different external stimuli such as mechanical force, temperature, or magnetic and electric fields, is currently of major interest in the materials science research community [52-54]. Superhydrophobic surfaces without high mechanical stability can hardly play their roles in the practical application. In fact, a large majority of superhydrophobic surfaces have very limited mechanical stability, they are prone to be damaged even after finger wipe [55]. Recently, a great deal of effort has been made to fabricate coatings, possessing the properties of superhydrophobicity and durability. Basically, hierarchical surface structure and low-surface-energy materials are both essential for the preparation of superhydrophobic surfaces [56]. The hierarchical dual-size surface roughness can allow air chamber to form between the water droplet and surface texture, thus facilitating water droplet to roll off easily [5,57-60]. Hierarchical structure synthesized by template based techniques $[2,12,61,62]$, chemical etching [63], deposition [64], electrodeposition[65], electrospinning [66], sol-gel method [67], and phase separation methods [68], electrochemical layer by layer deposition and colloidal assembly [69-71], plasma modification [72,73], chemical vapor deposition[74,75], calcinations[76], photolithography [77], UV-curable reaction [78], anodization methods [79], solution immersion [80], spray [81,82], and polymer imprinting [83] using polymers and metals. The most common method for preparing superhydrophobic surfaces is by spraying polymer solutions mixed with abundant inorganic particles to build rich multi-level structures which realize surface superhydrophobicity [40] through sol-gel method. Sol-gel methods preferred due to; 1 ) its mild operation situations without extra post-treatments such as high-energy etching or high-temperature calcination; 2) controlled surface morphology and enhanced coating properties [36]. Low-surface-energy materials comprise fluoride, hydrophobic polymers polyacrylate (PA) [84], poly (dimethylsiloxanes) (PDMS) [85], polyurethane (PU) [86], polypropylene (PP) [87] and polyaniline (PANI) [88]. Moreover, silicon, silica, polyelectrolyte/silica, polyelectrolyte/metal, raspberry-like particles and compounds with alkyl groups are used as low surface energy materials to fabricate superhydrophobic surface [8, 6]. Silica is one of the most popular used inorganic nanomaterials in the preparation of inorganic/organic composite materials $[16,89-93]$ through typical emulsion polymerization [94] and produced by numerous companies.Conventional silica particles possess plentiful hydroxyl groups on their surfaces. This often requires the surface modification of $\mathrm{SiO}_{2}$ to enhance the compatibility with organic matters, which is limited by cumbersome procedure and inefficient surface grafting [16]. Massproduced silica nanoparticles are available in the nanoscale and microscale at a very low cost. Silica nanoparticles are commonly used in the fields of biomedicine and material science; for instance, it is used as a composite coating material to harden polymers as it exhibits surface roughness in nanoscale, and their aggregation will create micrometer-sized roughness. Furthermore, their surface energy is very low and can be controlled by anchoring hydrophobic molecules or grafting with polymers [95]. Although silica nanoparticles are hydrophilic, their surface can be modified with a material having low surface energy; thus, they are popularly used to fabricate materials with a superhydrophobic surface [96]. $\mathrm{SiO}_{2}$ displays unique 


\section{Petroleum \& Petrochemical Engineering Journal}

properties including high hardness, low refractive index [97-99], excellent intrinsic characteristics such as nontoxicity, high thermal and mechanical stability, and easy structural regulation [100] making it one of the most researched and applied compounds in protective coatings [101]. The adhesives include epoxy resin [102-104], methyl phenyl silicone resin [105], benzoxazine [106], hydroxyl acrylic resin [107], commercial spray adhesives, double-sided tape [108]. The fabrication process involves forming either a bilayer coating containing top micro/nanoparticles layer and bottom binder layer or a monolayer coating composed of adhesive and other materials such as nanoparticles and solvents.

\section{Mechanism of the Sol Gel Process}

The sol-gel process offers a convenient method to fabricate porous glass films at ambient conditions because it is versatile, cost-effective and easy to combine with liquid deposition techniques that permit an accurate control of the coating thickness [99]. In a typical sol-gel process, the precursor is converted into a glassy material through a series of hydrolysis and polycondensation reaction. The most important factor for the precursor solution that influences the sol-gel process is the catalyst [109]. Referring to the chemistry of alkylsilanes sol-gel, it is well-known that the silica phase separation easily takes place when the $\mathrm{pH}$ value of the mixing solution is below and above the isoelectric point (IEP) of the reacting silanol. The formation of linear structures results from the acid catalyst reaction, while coagulation phenomena occur at base catalyst conditions [12]. It has been reported in the literature that incorporation of nanoparticles and microparticles in sol-gel or organicinorganic hybrid or polymer matrix can lead to superhydrophobicity $[110,111]$. Silica nanoparticles have also been used for the preparation of superhydrophobic surfaces after hydrophobization with low surface energy materials like octadecyltrichlorosilane, polydimethylsiloxane or perfluoroalkyl methacrylic copolymer [112,113]. Generally, there are two superhydrophobic states on a rough surface: Wenzel's state [114] and Cassie's State [115]. The former represents a wet contact mode of water and rough surface, where water droplets pin the surface and cannot slide on the surface. The latter represents a non-wet contact mode and water droplets can roll off easily owing to their low adhesive force [3]. Wenzel and Cassie theories [115-118] have been widely adopted in correlating the water contact angle (WCA) and surface textures and thus interpreting most of the experimental results. A combination of dual scale structure, i.e., surface roughness and low surface free energy results in artificial superhydrophobic surfaces. Attempts have been made in fabricating and mimicking such surfaces applying coatings with high WCA $[119,120]$.

\section{Literature Review}

Some literature discusses the development of fabricating transparent superhydrophobic surfaces [121123]. Some authors $[109,124,125]$ reported about the synthesis of artificial superhydrophobic surfaces [52,126131] by using a dispersion of silica (or titanium dioxide) nanoparticles to create an appropriate surface roughness and a fluorinated cover layer to modify the surface chemical nature [12]. Carla, et al. [132] demonstrated that chemical structure played a significant role on the topography and average roughness, so the roughness value of $125 \sim 150 \mathrm{~nm}$ was necessary for the formation of superhydrophobic surfaces. Different hydrophobic organosilane compound has been adopted for preparing superhydrophobic silica coating in combination with tetraethylorthosilicate (TEOS) [133-136]. Cai, et al. [137] and Wang and Xiong [138] used methyltriethoxysilane (MTES) and trimethylethoxysilane (TMES) as precursors to obtain hydrophobic antireflective coatings, respectively. Some other researchers used a cationic surfactant to regulate surface morphologies, Meng, et al. [139] used trimethylchlorosilane (TMCS) as surface modification agent, Gurav, et al. [140] used methyltrichlorosilane (MTS) and Purcar, et al. [141,142] used diethoxydimethylsilane(DEDMS) and hexadecyltrimethoxysilane and tetramethoxysilane (C16TMS/TMOS). In this section we give a brief survey about most of the published trials to fabricate superhydrophobic surfaces;

Alamri et al [52] develop an alternative, approach for the synthesis of a superhydrophobic magnetic-core/silicashell-grafted nanoparticles with superior and durable superhydrophobic performance under a variety of corrosive conditions. An, et al. [143] revealed that mountain-like protrusions appeared on the coated superhydrophobic cotton fabric surface after adding $\mathrm{SiO}_{2}$ particles into the fluorinate-containing polyacrylate, could capture more air for the WCA increase. The polyacrylate $/ \mathrm{SiO}_{2}$ hybrid coatings not only show good water repellency but also exhibit excellent mechanical properties. Aytug, et al. [144] fabricated a unique threedimensionality interconnected nanoporous coatings, which significantly suppresses Fresnel light reflections and provide enhanced transmission. Barkhudarov, et al. 


\section{Petroleum \& Petrochemical Engineering Journal}

[145] prepared superhydrophobic films using fluoroalkylsilanes and studied their effectiveness as corrosion inhibitor using neutron reflectivity technique. Basu et al [41] fabricate superhydrophobic surface by applying precursor mixtures containing hydrophobically modified silica (HMS) nanoparticles dispersed in sol-gel matrices on different substrates by spray and spin coating. Bravo, et al. [146] created transparent superhydrophobic films based on silica nanoparticles through a layer-bylayer method, calcinated at $550{ }^{\circ} \mathrm{C}$, otherwise, films would be removed from the substrate by rubbing with an alcohol-soaked wipe. Budunoglu, et al. [147] reported a thermally stable flexible and highly porous aerogel thin films having superhydrophobic properties using a colloidal dispersion of an intrinsically hydrophobic organosilane monomer at ambient conditions. Caldona, et al. [148] constructed superhydrophobic and superoleophilic nanocomposite film by incorporating $\mathrm{SiO}_{2}$ nanoparticles into the rubber modified polybenzoxazine by dipping and spraying technique [33]. Chen, et al. [36] fabricate a superhydrophobic and durable coating, through the synthesis of non-fluorine siloxane solution including tetraethoxysilane (TEOS), 3(methacryloyloxy)propyltrimethoxysilane, and hexadecyltrimethoxysilane (HTMS) via a facile one-pot method.

Cholewinski, et al. [149] reported a robust superhydrophobic bilayer coating containing polydimethylsiloxane (PDMS)-functionalized silica particles on top and an epoxy bonding layer at the base of the substrate. Ding et al [150] fabricated a superhydrophobic wood surface by casting a superhydrophobic coating, prepared by blending $\mathrm{TiO}_{2}$ nanoparticles with, w-bis (hydroxypropyl)-terminated fluorinated polysiloxane oligomer (PMSF) and, ๑-bis (hydrogen)-terminated poly(dimethylsiloxane) solutions. Ebert and Bhushan [151] prepared transparent superhydrophobic surfaces with a dip coating solution composed of surface-functionalized nanoparticles, tetrahydrofuran/isopropyl alcohol solvent and methylphenylsilicone resin, and the obtained surfaces showed wear resistance for potential commercial use in sliding and water jet experiments. Gao and McCarthy [152] prepared a perfectly hydrophobic surface with a water contact angle of more than $170^{\circ}$ on a silicon wafer by submerging it in a toluene solution of methyltrichlorosilane (MTCS) at room temperature. Goswami, et al. [11] present a simple, inexpensive sol-gel dip coating procedure which is based on the preparation of a macroscopic network with silica gel nanoparticles (NPs) through the hydrolysis of silicon alkoxide and condensation of silanols. Guo and Wang [18] develop an efficient one-step method to fabricate superhydrophobic silica-based polymer coatings by adding modified $\mathrm{SiO}_{2}$ nanoparticles through polymer matrix, and reported that the superhydrophobicity is well maintained in acidic and basic solutions, and this method possesses the advantages of being both simple and inexpensive as well as utilizing non-fluorine-containing compounds, which may bring great advantages in industrial applications, moreover, water repellency of the coating surface can be dramatically enhanced. Guo, et al. [3] fabricated a superhydrophobic surface-modified $\mathrm{SiO}_{2}$ /nylon 6,6 nanocomposite coating based on hydrophilic nylon 6,6. The adding of surface-modified $\mathrm{SiO}_{2}$ nanoparticles affected the coating surface energy and surface roughness, in turn influencing the wettability of the coating. Gurav, et al. [101] offer an effective and simple method for preparing self-cleaning superhydrophobic coatings on glass substrates, where the silica particles were easily modified by methyl groups using MTCS as a modifying agent; then applied to a glass substrate using a simple dipcoating technique.

Hsieh, et al. [153] produced superhydrophobic fluorocontaining silica coatings with good superhydrophobicity and superoleophobicity for sunflower oil on a wood substrate by spraying a mixture of perfluoroalkyl methacrylic polymer solution with $\mathrm{SiO}_{2}$ nanoparticles. $\mathrm{Hu}$, et al. [33] fabricate superhydrophobic and mechanically robust nanostructured films by modification of $\mathrm{SiO}_{2}$ nanoparticles with hexamethyldisilazane (HMDS) and the subsequent deposition of films by dip-coating a mixture of the as-synthesized superhydrophobic $\mathrm{SiO}_{2}$ nanoparticles, the hydroxyl acrylic resin (HAR) and the commercial $\mathrm{SiO}_{2}$ nanoparticles. Huang and Lin [154] fabricated superhydrophobic transparent surfaces by a sol-gel method with a silica-based coating in ethanol and subsequent coating of a low surface energy material like $1 \mathrm{H}, 1 \mathrm{H}, 2 \mathrm{H}, 2 \mathrm{H}$-perfluorooctyltrichlorosilane. Huang, et al. [155] developed a superhydrophobic paper via mixing MPS-modified $\mathrm{TiO}_{2}$ nanoparticles modified by silane coupling agent, 3-(trimethoxysilyl) propylmethacrylate (MPS), into cellulose pulp, after which the pulp mixture was diluted with distilled water to prepare hand sheets through a series of basic operation including vacuum filtration, dehydration, and curing. Huang, et al. [156] synthesized the fluorinated acrylate copolymers by solvent polymerization using ethanol and methyl ethyl ketone as solvents, and then the silica/fluorinated acrylate copolymers hybrid films were prepared by mixing silica sol and fluorinated acrylate copolymers. The hybrid films had good hydrophobicity, high thermal 


\section{Petroleum \& Petrochemical Engineering Journal}

stability and excellent mechanical properties of adhesion strength and pencil hardness. Hwang and Ahn [96] reported about the fabrication of a superhydrophobic surface using silica nanoparticles through the chemical reaction of the hydroxyl groups on the silica surface with aminopropyltriethoxysilane (APTES), followed by the condensation of palmitoyl chloride with the modified nanoparticles. Jiang and Guo [157] prepared robust superhydrophobic coating by spreading tungsten oxide microparticles onto epoxy resin treated glass substrates. Kamitani and Teranishi [158] have compared surfaces coated with fluoroalkylsilanes and polydimethylsiloxanes and reported that water contact angle of the surface coated with fluoroalkylsilanes was higher than that with polydimethylsiloxanes, but the sliding angle (SA) of the surface coated with fluoroalkylsilanes was higher than that with polydimethylsiloxanes[41]. Ke, et al. [10] develop polydimethylsiloxane (PDMS) based superhydrophobic surface by drop-coating a mixture of silica and PDMS on the glass substrate. Khalilabad and Yazdanshenas [159] demonstrated a dip-pad-dry coating method for depositing graphene oxide on cotton fibers. When combined with a subsequent reaction with MTCS, the method yielded polymethylsiloxane (PMS) nanofilaments on the fiber surface, which converted highly water-absorbing insulator cotton fabrics into textile-based substrate conductors with superhydrophobic properties. Khoo and Tseng [160] described in detail the hydrophobic engineering of threedimensional nano-architectures with various shapes, morphologies, and sizes using the phase separation of MTCS on glass and silica substrates. Kumar, et al. [161] reported a self-cleaning glycidoxypropyltriethoxysilane coatings with $15 \mathrm{wt} . \%$ loading of $10-20 \mathrm{~nm}$ silica by using organic-inorganic hybrid sol-gel method. Lakshmi, et al. [162] fabricated superhydrophobic sol-gel nanocomposite coatings by incorporating silica nanoparticles in an acidcatalyzed ethanol-water mixture sol of methyltriethoxysilane (MTEOS). The water repellency was further improved by the addition of fluoroalkylsilanes.

Latthe, et al. [133] develop semi-transparent superhydrophobic silica-polymethylmethacrylate (PMMA) coatings on the glass by using a hybrid sol-gel method. Li and Shen [163] designed a two-step dipping process with a silica sol and silica microsphere suspension for the preparation of superhydrophobic surfaces with a water contact angle of $170^{\circ}$. Li, et al. [164] fabricated a superhydrophobic polymer coating by a facile phase separation method through spraying the fluorinated acrylic random copolymer micelle solution. Liang, et al.
[165] developed a facile sol-gel method to create a superhydrophobic surface with tetraethylorthosilicate (TEOS) and vinyltriethoxysilane (VTES) as co-precursor following the typical Stöber method. Liu et al [7] investigated a fabrication of polyvinyl alcohol (PVA)/silica $\left(\mathrm{SiO}_{2}\right)$ composite polymer coating on wooden substrates with super repellency toward the water, low sliding angles, low contact angle hysteresis, and relatively better mechanical robustness. They reported that the composite polymer slurry, consisting of well-mixing $\mathrm{SiO}_{2}$ particles and PVA, is prepared simply and subsequently coated over wooden substrates with good adhesion. The $\mathrm{SiO}_{2}$ particles act as a solid plasticizer capable of enhancing the chemical and mechanical properties and improve the dimensional stability of the $\mathrm{PVA} / \mathrm{SiO}_{2}$ composite polymer [166]. Liu, et al. [167] fabricated a superhydrophobic vinyltriethoxysilane (VTES)- modified silica coating on a wood surface using a one-step hydrothermal method. Liu, et al. [168] took candle soot as an intermediate to fabricate superhydrophobic and transparent surfaces on glass. Luo, et al. [169] fabricated an almost transparent polyurethane/silica composite superhydrophobic coating by a double-step sol-gel route, which improved the dispersion of $\mathrm{SiO}_{2}$ particles obviously. Mahadik, et al. [24] presented the combined approach to fabricate recoverable superhydrophobic surface, more in line hierarchical texture with low energy surface used to fabricate superhydrophobic surface. This approach involves a direct growth of dual scale silica particles using dip coating deposition technique and surface energy reduction by surface modification with trimethylchlorosilane (TMCS). After necessary surface modification, a highly thermally stable, mechanically robust and recoverable superhydrophobic surfaces have been fabricated. Manca, et al. [12] generate robust superhydrophobic surfaces exhibiting a self-cleaning behavior by simply depositing a sol-gel-based coating containing trimethyl siloxane (TMS) surfacefunctionalized silica nanoparticles onto a precoated silica gel layer. Also, they [12] reported on the synthesis of superhydrophobic antireflective coatings using a bilayer approach through the sol-gel process. They used trimethylsilanized silica nanoparticles (Aerosil) partially embedded into an organosilica binder matrix and claimed that the cured coatings at $350^{\circ} \mathrm{C}$ have retained the superhydrophobicity even after $2000 \mathrm{~h}$ of outdoor exposure [11].

Martin and Bhushan [105] also prepared the transparent, wear-resistant, superhydrophobic and superoleophobic PDMS/binder surfaces by spraying a mixture of hydrophobic silica nanoparticles, 


\section{Petroleum \& Petrochemical Engineering Journal}

tetrahydrofuran, isopropyl alcohol and methyl phenyl silicone resin with subsequent deposition of fluorosilane, where the PDMS substrate was required to be chemically activated by ultraviolet-ozone treatment. Ogihara, et al. [170] fabricated superhydrophobic and transparent silica nanoparticle films on glass plates by spray coating suspensions containing 1-propanol and hydrophobic nanoparticles that were modified with dodecyl groups. Pilotek and Schmidt [110] have obtained sol-gel hydrophobic coatings by dispersing silica nanoparticles in a matrix containing tetraethylorthosilicate (TEOS) and fluoroalkyl silane, then investigate the wettability of these microstructured coatings [41]. Prakash, et al. [171] reported the preparation of silica aerogel thin films at ambient pressure without the need of supercritical extraction. Prasad, et al. [172] prepare transparent hydrophobic and superhydrophobic polyamide $12-\mathrm{SiO}_{2}$ nanocomposite transparent coatings on the glass surface. The coatings have been prepared through the successive spin coating of hydrophobically modified silica (HMS) dispersed onto polymer films. Psarski et al [104] developed superhydrophobic coating via incorporating glass microbeads and $\mathrm{Al}_{2} \mathrm{O}_{3}$ nanoparticles in epoxy resin with subsequent surface sandblasting and wet chemical hydrophobization. Ramezani, et al. [173] studied the twostep dip coating via a sol-gel process to prepare superhydrophobic silica films by a coating of silica alcohol and subsequent modification with isooctyltrimethoxysilane as a hydrophobic agent. Rao and his coworkers [134,174] have prepared superhydrophobic silica film by introducing methyl groups in the silica film by post-synthesis grafting from solutions using trimethylchlorosilane (TMCS) and HMDS silylating agents [41]. Shang et al [16] reported about fabrication of superhydrophobic surface with core/shell $\mathrm{SiO}_{2} /$ fluoro-containing polymer $\left(\mathrm{SiO}_{2} / \mathrm{PFS}\right)$ composite particles via one-step emulsion polymerization and the drop-coating process has been presented. The asprepared superhydrophobic $\mathrm{SiO}_{2} / \mathrm{PFS}$ coating has a water contact angle up to $171^{\circ}$ mainly due to the combination of the hierarchical micro/nano-scale roughness and the low surface free energy. Shang, et al. [175] prepared superhydrophobic silica coatings by spraying an ethanol suspension consisting of silica sol and silica microspheres followed by hydrophobic treatment with $1 \mathrm{H}, 1 \mathrm{H}, 2 \mathrm{H}, 2 \mathrm{H}-$ perfluorodecyltriethoxysilane (PFDTS) solution. Shang, et al. [176] have developed optically transparent superhydrophobic silica-based films by means of sol-gel processing and self-assembly. The resultant silica-based coatings showed advancing and receding water contact angles of approximately 165/115 respectively, and hence the water drops do not roll on such coatings due to the high contact angle hysteresis. Shang, et al. [175] reported a simple, versatile strategy for creating a superhydrophobic surface via spraying the as-prepared silica suspension containing silica sol and silica microspheres on the substrate, using $1 \mathrm{H}, 1 \mathrm{H}, 2 \mathrm{H}, 2 \mathrm{H}-$ perfluorodecyltriethoxysilane to form hydrophobic groups.

Shi and Xiao [177] fabricate superhydrophobic nanocomposite coating by spraying nanocomposite dispersion containing hydrophobic silica nanoparticle and polyvinylidene fluoride (PVDF) on the paper surface. Shirgholami, et al. [178] recently reported the deposition of polymethylsilsesquioxane (PMSQ) nanostructures onto the surface of the cotton fabric and adopted the subsequent modification in a toluene solution of MTCS at room temperature with different duration times to achieve superhydrophobic cotton fabrics. Song, et al. [179] proposed the fabrication of hydrogel and polymeric spheres over a superhydrophobic substrate for potential application in tissue engineering or as support for cell expansion. Su, et al. [19] fabricated organic-inorganic superhydrophobic polyester textiles with strong durability and robustness for practical applications in oil spill accidents and industrial sewage emission via a very simple approach with cheap tetraethylorthosilicate (TEOS) and polydimethylsiloxane (PDMS (OH) as reactants using $\mathrm{HCl}$ as catalysts. The textile possessed excellent water repellency with a contact angle of $160^{\circ}$. The formation process of the superhydrophobic surface included the first hydrolysis-condensation of TEOS to generate silica, the subsequent gradual formation of micro-aggregated silica to construct roughness under the driving force of the extreme polarity difference between silica and $\mathrm{PDMS}(\mathrm{OH})$, and the further crosslinking reaction of $\mathrm{Si}-\mathrm{OH}$ groups between micro-aggregated silica and $\mathrm{PDMS}(\mathrm{OH})$ at the later reaction stage. Su, et al. [180] have embedded nano silica particles on epoxy coated glass surface and subsequently coated with fluoroalkylsilane to achieve superhydrophobicity. Fluroalkylsilanes are either incorporated in the hybrid mixture or applied as a topcoat to decrease the surface energy $[110,124,180,181]$. Sun, et al. [182] constructed titanium dioxide nanoparticles (NPs) on a wood surface through a hydrothermal method and then modified the rough structure with sodiumdodecylsulfate (SDS), to yield an apparently superhydrophobic wood surface with a water contact angle of about $154^{\circ}$. Tang, et al. [183] fabricated a transparent superhydrophobic coating on paper by dip coating paper samples in silica ethanol sol through cohydrolysis of TEOS and hexadecyltrimethoxysilane (HDTMS), followed by curing coating overnight at indoor 


\section{Petroleum \& Petrochemical Engineering Journal}

temperature. Tu, et al. [184] prepared superhydrophobic coating by spraying a waterborne perfluoroalkyl methacrylic copolymer emulsion mixed with $50 \mathrm{wt} . \%$ $\mathrm{TiO}_{2}$ nanoparticles on polydimethylsiloxane pre-coated wood. Wang and Xiong $[138,185]$ prepared two different rough coatings and compared the influence on the transmittance and wettability. The wettability on the surface with micro-/nano-hierarchical structure was relatively stable with respect to the surface with low roughness. And he indicated that the air bubbles trapped in the surface were also an important factor to influence the hydrophobicity. Wang, et al. [186] synthesized silica particles on wood surfaces via a sol-gel process and subsequently modified hydrophilic particles with octadecyltrichlorosilane via a chemical vapor deposition (CVD) method to finally obtain a superhydrophobic wood surface with a water contact angle of $164^{\circ}$. Wang, et al. [187] fabricated zinc oxide nanorods on a wood surface using a wet chemical approach followed by modification with stearic acid, thereby endowing the wood surface with superhydrophobic properties and yielding a water contact angle value of about $153.5^{\circ}$.

Wang, et al. [188] developed a novel transplantable superhydrophobic film on a pretreatment glazed tile by spraying $1 \mathrm{H}, 1 \mathrm{H}, 2 \mathrm{H}, 2 \mathrm{H} \quad$ perfluorodecyltriethoxysilane solution with $32.5 \mathrm{wt} . \% \mathrm{SiO}_{2}$. Wei, et al. [189] presented a simple way to prepare a superhydrophobic thin film which was composed by one-step coating with modified silica nanoparticles. Wu, et al. [190] have developed transparent superhydrophobic hard coatings by sol-gel method with silica filler resulting in rough surfaces with a lotus-like structure but the obtained water contact angle was about $123^{\circ}$ [191]. Wu, et al. [192] produced durable superhydrophobic surfaces by spraying, dipping and brushing emulsion composed of nanoparticles and epoxy resin on different substrates. Xing et al [5] synthesize various nano-coatings with different particle stacking manner (i.e., micro- and/or nano-roughness) by using a series of dendrimer-like porous silica nanospheres (DPSNs) with tunable particle sizes and surface pore sizes as building blocks, based on paint- and dip-coating methods. Xu, et al. [193] fabricated a hierarchically structured lotus-leaf-like superhydrophobic films by spraying the polystyrene/ $\mathrm{SiO}_{2}$ core/shell nanoparticles as a coating skeleton and the polydimethylsiloxane as hydrophobic interconnection and reported average transmittance greater than $95 \%$ and a water contact angle of $162^{\circ}$. Xue, et al. [194] fabricated a superhydrophobic textile with durability against abrasion and laundering through three steps including the creation of rough structure by alkali etching, modification with mercapto siloxane and hydrophobization with fluorine-containing materials. Yang and Deng [195] fabricated superhydrophobic surfaces on paper by multi-layer deposition of polydiallyldimethylammonium chloride (PDADMAC) and silica particles, after which the samples were modified by $1 \mathrm{H}, 1 \mathrm{H}, 2 \mathrm{H}, 2 \mathrm{H}-$ perfluorooctyltriethoxysilane (PFOTS). Zhang and his coworkers [196] fabricated micro-nano hierarchically structured nylon 6,6 surfaces by a phase separation method and the wettability of the surfaces changed from super hydrophilicity to superhydrophobicity after further modification by low surface energy material. Zhang and Seeger [197] successfully prepared a superhydrophobic and superoleophilic textile as a membrane for oil-water separation and selective oil absorption. Zhang, et al. [40] proposed a feasible approach to fabricate a durable superhydrophobic coating with litchi-like structure by evenly growing nano- $\mathrm{SiO}_{2}$ particles on polyethersulfone (PES) submicron particles. Zhang, et al. [198] fabricated novel nanocomposite coatings with the transmittance values of $96.86 \% \sim 97.34 \%$. They pointed out that the high porosity is not good for the transmittance and durability, and furthermore he got a suitable refractive index of 1.21 by controlling the porosity size. Zhao, et al. [199] synthesize silica coated multiwalled carbon nanotube (MWCNTs) composites ( $\mathrm{SiO}_{2}$ /MWCNTs) by means of the sol-gel method. They reported that the surface energy of materials was greatly reduced due to modifying $\mathrm{SiO}_{2}$ / MWCNTs with vinyltriethoxysilane, in addition to the rough structure of carbon nanotubes. Consequently, superhydrophobic surface with maximum static water contact angle of $156^{\circ}$ and sliding angle of $3.5^{\circ}$ was fabricated.

Zhao, et al. [200] prepared a superhydrophobic coating solution via co-hydrolysis and condensation of TEOS and a fluorinated alkylsilane under the alkaline condition on various substrates such as cotton and filter paper. The superhydrophobic coatings exhibited good transparency, which the water contact angle of $170^{\circ}$ and a sliding angle of no more than $10^{\circ}$. Zhong, et al. [201] developed transparent and durable superhydrophobic bilayer coatings containing hydrophobic silica particles on top and an epoxy resin bonding layer at the base. Hydrophobic silica nanoparticles prepared by using the co-precursors of tetraethylorthosilicate (TEOS) and methyltriethoxysilane (MTES), and then highly dispersed in ethanol to form a brush-coating suspension. They concluded that the stability of the coating decreases with decreasing of silica concentration. Zhou, et al. [202] reported a durable and robust superhydrophobic textile coating by mixing polydimethylsiloxane (PDMS) with 


\section{Petroleum \& Petrochemical Engineering Journal}

fluorinated alkylsilane (FAS) functionalized silica nanoparticles and FAS. Zhou, et al. [203] prepared a superhydrophobic polydopamine-coated copper foam for oil/water separation by utilizing the self-polymerization of dopamine to enhance the interface bonding strength between the copper foam and Ag nanoparticles. Moreover, stable $\mathrm{Fe}_{3} \mathrm{O}_{4}$-PDA-Ag nanoparticles with core-shell hierarchical structures were prepared via step wisely cladding dopamine and silver particles on the surfaces of $\mathrm{Fe}_{3} \mathrm{O}_{4}[204]$.

\section{Conclusion}

Fabrication of superhydrophobic surfaces is crucial for commercial applications of these surfaces in the fields of self-cleaning, water repellency and corrosion resistance. A sol-gel method is a simple approach for the fabrication of the superhydrophobic silica coating, where surface modification of the $\mathrm{SiO}_{2}$ and the curing temperature are very important for obtaining stable superhydrophobic surfaces. The hydrophobicity of the surface depends on the thickness of the deposited films. These hydrophobic coating materials alter surface wettability from hydrophilic to hydrophobic one. The enhancement of the mechanical properties can be attributed to the fact that the $\mathrm{SiO}_{2}$ nanoparticles act as a solid plasticizer capable of enhancing the chemical and mechanical properties, and enhance the stability of the water contact angle of the composite coating.

\section{References}

1. Sun T, Feng L, Gao X, Jiang L (2005) Bioinspired surfaces with special wettability. Acc Chem Res 38(8): 644-652.

2. Sun M, Luo C, Xu L, Ji H, Ouyang $Q$ et al. (2005) Artificial lotus leaf by nanocasting. Langmuir 21(19): 8978-8981.

3. Guo Y, Wang Q, Wang T (2011) A facile process for preparing superhydrophobic films with surfacemodified $\mathrm{SiO}_{2}$ /nylon 6, 6 nanocomposite. Journal of materials science 46(11): 4079-4084.

4. Wang JY, Zhou GG, Xu WH, Liu WL, Cai XX, et al. (2014) Facile synthesis of a superhydrophobic surface with modified hollow silica nanoparticles. RSC Advances 4(93): 51603-51608.

5. Xing Y, Du X, Li X, Huang H, Li J, et al. (2018) Tunable dendrimer-like porous silica nanospheres: Effects of structures and stacking manners on surface wettability. Journal of Alloys and Compounds 732: 7079.

6. Xu J, Liu Y, Du W, Lei W, Si X, et al. (2017) Superhydrophobic silica antireflective coatings with high transmittance via one-step sol-gel process. Thin Solid Films 631: 193-199.

7. Liu F, Wang S, Zhang M, Ma M, Wang C, et al. (2013) Improvement of mechanical robustness of the superhydrophobic wood surface by coating $\mathrm{PVA} / \mathrm{SiO}_{2}$ composite polymer. Applied Surface Science 280: 686-692.

8. Li K, Zeng X, Li H, Lai X (2014) Fabrication and characterization of stable superhydrophobic fluorinated-polyacrylate/silica hybrid coating. Applied Surface Science 298: 214-220.

9. Liu K, Jiang L (2011) Bio-inspired design of multiscale structures for function integration. Nano Today 6(2): 155-175.

10. Ke $\mathrm{Q}, \mathrm{Fu} \mathrm{W}$, Jin $\mathrm{H}$, Zhang $\mathrm{L}$, Tang $\mathrm{T}$, et al. (2011) Fabrication of mechanically robust superhydrophobic surfaces based on silica micro-nanoparticles and polydimethylsiloxane. Surface and Coatings Technology 205(21-22): 4910-4914.

11. Goswami D, Medda SK, De G (2011) Superhydrophobic films on glass surface derived from trimethylsilanized silica gel nanoparticles. ACS applied materials \& interfaces 3(9): 3440-3447.

12. Manca M, Cannavale A, De Marco L, Arico AS, Cingolani R, et al. (2009) Durable superhydrophobic and antireflective surfaces by trimethylsilanized silica nanoparticles-based sol-gel processing. Langmuir 25(11): 6357-6362.

13. Marmur A (2004) The lotus effect: superhydrophobicity and metastability. Langmuir 20(9): 3517-3519.

14. Barthlott W, Neinhuis C (1997) Purity of the sacred lotus, or escape from contamination in biological surfaces. Planta 202(1): 1-8.

15. Manca M, Cortese B, Viola I, Aricò AS, Cingolani R, Gigli G (2008) Influence of chemistry and topology effects on superhydrophobic CF4-plasma-treated poly 


\section{Petroleum \& Petrochemical Engineering Journal}

(dimethylsiloxane)(PDMS). Langmuir 24(5): 18331843.

16. Shang QQ, Liu H, Xiao GM (2013) Facile Fabrication of Superhydrophobic Surface via $\mathrm{SiO}_{2}$ /FluoroContaining Polymer Composite Particles. Advanced Materials Research 634: 1922-1926.

17. Ganesh VA, Raut HK, Nair AS, Ramakrishna S (2011) A review on self-cleaning coatings. Journal of Materials Chemistry 21(41): 16304-16322.

18. Guo Y, Wang Q (2010) Facile approach in fabricating superhydrophobic coatings from silica-based nanocomposite. Applied Surface Science 257(1): 3336.

19. Su X, Li H, Lai X, Zhang L, Wang J, et al. (2017) VaporLiquid Sol-Gel Approach to Fabricating Highly Durable and Robust Superhydrophobic Polydimethylsiloxane@Silica Surface on Polyester Textile for Oil-Water Separation. ACS applied materials \& interfaces 9(33): 28089-28099.

20. Jia S, Liu M, Wu Y, Luo S, Qing Y, et al. (2016) Facile and scalable preparation of highly wear-resistance superhydrophobic surface on wood substrates using silica nanoparticles modified by VTES. Applied Surface Science 386: 115-124.

21. Yan YY, Gao N, Barthlott W (2011) Mimicking natural superhydrophobic surfaces and grasping the wetting process: A review on recent progress in preparing superhydrophobic surfaces. Advances in colloid and interface science 169(2): 80-105.

22. Erbil HY, Demirel AL, Avcl Y, Mert O (2003) Transformation of a simple plastic into a superhydrophobic surface. Science 299(5611): 13771380.

23. Gowri VS, Almeida L, De Amorim MTP, Pacheco NC, Souto AP, et al. (2010) Functional finishing of polyamide fabrics using ZnO-PMMA nanocomposites. Journal of materials science 45(9): 2427-2435.

24. Mahadik SA, Mahadik D, Parale V, Wagh P, Gupta S, et al. (2012) Recoverable and thermally stable superhydrophobic silica coating. Journal of sol-gel science and technology 62(3): 490-494.
25. Lau KK, Bico J, Teo KB, Chhowalla M, Amaratunga GA, et al. (2003) Superhydrophobic carbon nanotube forests. Nano letters 3(12): 1701-1705.

26. Feng L, Song Y, Zhai J, Liu B, Xu J, et al. (2003) Creation of a superhydrophobic surface from an amphiphilic polymer. Angewandte Chemie International Edition 42(7): 800-802.

27. Feng L, Li S, Li H, Zhai J, Song Y, et al. (2002) Super-hydrophobic surface of aligned polyacrylonitrile nanofibers. Angewandte Chemie International Edition 41(7): 1221-1223.

28. Pourjavadi A, Esmaili H, Nazari M (2018) Facile fabrication of superhydrophobic nanocomposite coating using modified silica nanoparticles and nonfluorinated acrylic copolymer. Polymer Bulletin, pp: 1-15.

29. Bhushan B, Jung YC (2011) Natural and biomimetic artificial surfaces for superhydrophobicity, selfcleaning, low adhesion, and drag reduction. Progress in Materials Science 56(1): 1-108.

30. Yang J, Zhang Z, Men X, Xu X, Zhu X (2010) Reversible superhydrophobicity to superhydrophilicity switching of a carbon nanotube film via alternation of UV irradiation and dark storage. Langmuir 26(12): 10198-10202.

31. Banerjee I, Pangule RC, Kane RS (2011) Antifouling coatings: recent developments in the design of surfaces that prevent fouling by proteins, bacteria, and marine organisms. Adv Mater 23(6): 690-718.

32. Nishino T, Meguro M, Nakamae K, Matsushita M, Ueda Y (1999) The lowest surface free energy based on$\mathrm{CF}_{3}$ alignment. Langmuir 15(13): 4321-4323.

33. Hu C, Chen W, Li T, Ding Y, Yang H, et al. (2018) Constructing non-fluorinated porous superhydrophobic $\mathrm{SiO}_{2}$-based films with robust mechanical properties. Colloids and Surfaces A: Physicochemical and Engineering Aspects 551: 65-73.

34. Mammen L, Deng $\mathrm{X}$, Untch $\mathrm{M}$, Vijayshankar D, Papadopoulos P, et al. (2012) Effect of nanoroughness on highly hydrophobic and superhydrophobic coatings. Langmuir 28(42): 15005-15014. 


\section{Petroleum \& Petrochemical Engineering Journal}

35. Wang S, Jiang L (2007) Definition of superhydrophobic states. Advanced Materials 19(21): 3423-3424.

36. Chen X, Chen Y, Jin T, He L, Zeng Yu, et al. (2018) Fabrication of superhydrophobic coating from nonfluorine siloxanes via a one-pot sol-gel method. Journal of Materials Science 53(16): 11253-11264.

37. Xue Z, Wang S, Lin L, Chen L, Liu M, et al. (2011) A novel superhydrophilic and underwater superoleophobic hydrogel-coated mesh for oil/water separation. Advanced Materials 23(37): 4270-4273.

38. Zhou Y, Li M, Zhong X, Zhu Z, Deng P, et al. (2015) Hydrophobic composite coatings with photocatalytic self-cleaning properties by micro/nanoparticles mixed with fluorocarbon resin. Ceramics International 41(4): 5341-5347.

39. Sheng X, Zhang J (2011) Directional motion of water drop on ratchet-like superhydrophobic surfaces. Applied Surface Science 257(15): 6811-6816.

40. Zhang X, Liu Z, Zhang X, Li Y, Wang H, et al. (2018) High-adhesive superhydrophobic litchi-like coatings fabricated by in-situ growth of nano-silica on polyethersulfone surface. Chemical Engineering Journal 343: 699-707.

41. Basu BJ, Hariprakash V, Aruna S, Lakshmi R, Manasa J (2010) Effect of microstructure and surface roughness on the wettability of superhydrophobic sol-gel nanocomposite coatings. Journal of sol-gel science and technology 56(3): 278-286.

42. Koch K, Bhushan B, Barthlott W (2008) Diversity of structure, morphology and wetting of plant surfaces. Soft Matter 4(10):1943-1963.

43. Samuel JJS, Ruther P, Frerichs H-P, Lehmann M, Paul 0 , et al. (2005) A simple route towards the reduction of surface conductivity in gas sensor devices. Sensors and Actuators B: Chemical 110(2): 218-224.

44. Chen $Q$ de Leon A, Advincula RC (2015) Inorganicorganic thiol-ene coated mesh for oil/water separation. ACS applied materials \& interfaces 7(33):18566-18573.

45. Tian X, Jokinen V, Li J, Sainio J, Ras RH (2016) Unusual dual superlyophobic surfaces in oil-water systems: the design principles. Advanced Materials 28(48):10652-10658.

46. Cheng M, Song M, Dong H, Shi F (2015) Surface Adhesive Forces: A Metric Describing the Drag-Reducing Effects of Superhydrophobic Coatings. Small 11(14):1665-1671.

47. Tang Y, Fu T, Liu Q, Luo W (2015) Copper based superhydrophobic microchannels: fabrication and its effect on friction reduction. Materials Science and Technology 31(6): 730-736.

48. Peng L, Lei W, Yu P, Luo Y (2016) Polyvinylidene fluoride (PVDF)/hydrophobic nano-silica $\left(\mathrm{H}-\mathrm{SiO}_{2}\right)$ coated superhydrophobic porous materials for water/oil separation. RSC Advances 6(13): 1036510371.

49. He M, Wang J, Li H, Song Y (2011) Super-hydrophobic surfaces to condensed micro-droplets at temperatures below the freezing point retard ice/frost formation. Soft Matter 7(8): 3993-4000.

50. Zhao Y, Cho SK (2006) Microparticle sampling by electrowetting-actuated droplet sweeping. Lab Chip 6(1): 137-144.

51. Shang Q, Zhou Y (2016) Fabrication of transparent superhydrophobic porous silica coating for selfcleaning and anti-fogging. Ceramics International 42(7): 8706-8712.

52. Alamri H, Al-Shahrani A, Bovero E, Khaldi T, Alabedi G, et al. (2018) Self-cleaning superhydrophobic epoxy coating based on fibrous silica-coated iron oxide magnetic nanoparticles. J Colloid Interface Sci 513: 349-356.

53. Rao JP, Gruenberg P, Geckeler KE (2015) Magnetic zero-valent metal polymer nanoparticles: Current trends, scope, and perspectives. Progress in Polymer Science 40: 138-147.

54. Nagappan S, Ha CS (2015) Emerging trends in superhydrophobic surface based magnetic materials: fabrications and their potential applications. Journal of Materials Chemistry A 3(7): 3224-3251.

55. Scarratt LR, Steiner U, Neto C (2017) A review on the mechanical and thermodynamic robustness of superhydrophobic surfaces. Advances in colloid and interface science 246: 133-152. 


\section{Petroleum \& Petrochemical Engineering Journal}

56. Su B, Tian Y, Jiang L (2016) Bioinspired interfaces with superwettability: from materials to chemistry. Journal of the American Chemical Society 138(6): 1727-1748.

57. Su Y, Ji B, Zhang K, Gao H, Huang Y, et al. (2010) Nano to micro structural hierarchy is crucial for stable superhydrophobic and water-repellent surfaces. Langmuir 26(7): 4984-4989.

58. Gao L, McCarthy TJ (2006) The "lotus effect" explained: two reasons why two length scales of topography are important. Langmuir 22(7): 29662967.

59. Nosonovsky M (2007) Multiscale roughness and stability of superhydrophobic biomimetic interfaces. Langmuir 23(6): 3157-3161.

60. Bittoun E, Marmur A (2012) The role of multiscale roughness in the lotus effect: is it essential for superhydrophobicity? Langmuir 28(39): 13933-13942.

61. Zhang L, Wu J, Wang Y, Long Y, Zhao N, et al. (2012) Combination of bioinspiration: a general route to superhydrophobic particles. Journal of the American Chemical Society 134(24): 9879-9881.

62. Bico J, Marzolin C, Quéré D (1999) Pearl drops. EPL (Europhysics Letters) 47(2): 220-226.

63. Du X, Liu X, Chen H, He J (2009) Facile fabrication of raspberry-like composite nanoparticles and their application as building blocks for constructing superhydrophilic coatings. The Journal of Physical Chemistry C 113(21): 9063-9070.

64. Lv T, Cheng Z, Zhang E, Kang H, Liu Y, et al. (2017) Self-Restoration of Superhydrophobicity on Shape Memory Polymer Arrays with Both Crushed Microstructure and Damaged Surface Chemistry. Small 13(4).

65. Shi F, Wang Z, Zhang X (2005) Combining a Layer-by-Layer Assembling Technique with Electrochemical Deposition of Gold Aggregates to Mimic the Legs of Water Striders. Advanced Materials 17(8):1005-1009.

66. Lu X, Wang C, Wei Y (2009) One-Dimensional Composite Nanomaterials: Synthesis by Electrospinning and Their Applications. Small 5(21): 2349-2370.
67. Li F, Du M, Zheng Z, Song Y, Zheng Q (2015) A facile, multifunctional, transparent, and superhydrophobic coating based on a nanoscale porous structure spontaneously assembled from branched silica nanoparticles. Advanced Materials Interfaces 2(13).

68. Zhu T, Cai C, Guo J, Wang R, Zhao N, et al. (2017) Ultra Water Repellent Polypropylene Surfaces with Tunable Water Adhesion. ACS Appl Mater Interfaces 9(11): 10224-32.

69. Khorsand S, Raeissi K, Ashrafizadeh F (2014) Corrosion resistance and long-term durability of super-hydrophobic nickel film prepared by electrodeposition process. Applied Surface Science 305: 498-505.

70. Liu Y, Yin X, Zhang J, Yu S, Han Z, et al. (2014) A electro-deposition process for fabrication of biomimetic super-hydrophobic surface and its corrosion resistance on magnesium alloy. Electrochimica Acta 125: 395-403.

71. Xu L, Tong F, Lu X, Lu K, Lu Q (2015) Multifunctional polypyrene/silica hybrid coatings with stable excimer fluorescence and robust superhydrophobicity derived from electrodeposited polypyrene films. Journal of Materials Chemistry C 3(9): 2086-2092.

72. Yung CS, Tomlin NA, Heuerman K, Keller MW, White MG, et al. (2018) Plasma modification of vertically aligned carbon nanotubes: Superhydrophobic surfaces with ultra-low reflectance. Carbon 127: 195201.

73. Xu P, Pershin L, Mostaghimi J, Coyle TW (2018) Efficient one-step fabrication of ceramic superhydrophobic coatings by solution precursor plasma spray. Materials Letters 211: 24-27.

74. Huang L, Lau S, Yang H, Leong E, Yu S, Prawer S (2005) Stable superhydrophobic surface via carbon nanotubes coated with a $\mathrm{ZnO}$ thin film. The Journal of Physical Chemistry B 109(16): 7746-7748.

75. Tadanaga K, Kitamuro K, Matsuda A, Minami T (2003) Formation of superhydrophobic alumina coating films with high transparency on polymer substrates by the sol-gel method. Journal of sol-gel science and technology 26(1-3): 705-708.

76. Nakajima A, Fujishima A, Hashimoto K, Watanabe T (1999) Preparation of transparent superhydrophobic 


\section{Petroleum \& Petrochemical Engineering Journal}

boehmite and silica films by sublimation of aluminum acetylacetonate. Advanced Materials 11(16): 13651368.

77. Sung YH, Kim YD, Choi H-J, Shin R, Kang S, et al. (2015) Fabrication of superhydrophobic surfaces with nano-in-micro structures using UV-nanoimprint lithography and thermal shrinkage films. Applied Surface Science 349: 169-173.

78. Sparks BJ, Hoff EF, Xiong L, Goetz JT, Patton DL (2013) Superhydrophobic hybrid inorganic-organic thiol-ene surfaces fabricated via spray-deposition and photopolymerization. ACS applied materials \& interfaces 5(5): 1811-1817.

79. Wu W, Wang X, Wang D, Chen M, Zhou F, et al. (2009) Alumina nanowire forests via unconventional anodization and super-repellency plus low adhesion to diverse liquids. Chemical Communications 9: 10431045.

80. Liu C, Wang S, Shi J, Wang C (2011) Fabrication of superhydrophobic wood surfaces via a solutionimmersion process. Applied Surface Science 258(2): 761-765.

81. Zhu X, Zhang Z, Ge B, Men X, Zhou X (2014) Fabrication of a superhydrophobic carbon nanotube coating with good reusability and easy repairability. Colloids and Surfaces A: Physicochemical and Engineering Aspects 444: 252-256.

82. Yang J, Song H, Ji H, Tang H, Li C (2013) Spray-Coated Metal Hexadecanoate-Based Coatings with Robust Superhydrophobicity and Repairability. Journal of Dispersion Science and Technology 34(10): 13421346.

83. Guo C, Feng L, Zhai J, Wang G, Song Y, et al. (2004) Large-Area Fabrication of a Nanostructure-Induced Hydrophobic Surface from a Hydrophilic Polymer. ChemPhysChem 5(5): 750-753.

84. Teare D, Spanos C, Ridley P, Kinmond E, Roucoules V, et al. (2002) Pulsed plasma deposition of superhydrophobic nanospheres. Chemistry of materials 14(11): 4566-4571.

85. Li K, Zeng X, Li H, Lai X, Ye C, et al. (2013) Study on the wetting behavior and theoretical models of polydimethylsiloxane/silica coating. Applied Surface Science 279: 458-463.
86. Jiang C, Zhang Y, Wang Q, Wang T (2013) Superhydrophobic polyurethane and silica nanoparticles coating with high transparency and fluorescence. Journal of Applied Polymer Science 129(5): 2959-2965.

87. Lv Y, Yu X, Jia J, Tu S-T, Yan J, et al. (2012) Fabrication and characterization of superhydrophobic polypropylene hollow fiber membranes for carbon dioxide absorption. Applied energy 90(1): 167-174.

88. Weng CJ, Chang CH, Lin IL, Yeh JM, Wei Y, et al. (2012) Advanced anticorrosion coating materials prepared from fluoro-polyaniline-silica composites with synergistic effect of superhydrophobicity and redox catalytic capability. Surface and Coatings Technology 207: 42-49.

89. Panthi G, Park M, Kim HY, Park SJ (2015) Electrospun polymeric nanofibers encapsulated with nanostructured materials and their applications: a review. Journal of Industrial and Engineering Chemistry 24: 1-13.

90. El-hoshoudy A, Desouky S, Al-Sabagh A, Betiha M, MY $\mathrm{E}-\mathrm{k}$, et al. (2017) Evaluation of solution and rheological properties for hydrophobically associated polyacrylamide copolymer as a promised enhanced oil recovery candidate. Egyptian Journal of Petroleum 26(3): 779-785.

91. El-Hoshoudy A, Desouky S, Elkady M, Alsabagh A, Betiha $M$, et al. (2015) Investigation of optimum polymerization conditions for synthesis of crosslinked polyacrylamide-amphoteric surfmer nanocomposites for polymer flooding in sandstone reservoirs. International Journal of Polymer Science, pp: 14.

92. El-Hoshoudy A, Desouky S (2018) Synthesis and evaluation of acryloylated starch-g-poly (Acrylamide/Vinylmethacrylate/1-Vinyl-2-

pyrrolidone) crosslinked terpolymer functionalized by dimethylphenylvinylsilane derivative as a novel polymer-flooding agent. International journal of biological macromolecules 116: 434-442.

93. El-hoshoudy A (2018) Quaternary ammonium based surfmer-co-acrylamide polymers for altering carbonate rock wettability during water flooding. Journal of Molecular Liquids 250: 35-43. 


\section{Petroleum \& Petrochemical Engineering Journal}

94. El-hoshoudy ANMB (2018) Emulsion Polymerization Mechanism. Recent Research in Polymerization. InTech.

95. Sun J, Wang J (2015) The fabrication of superhydrophobic glass fiber-reinforced plastic surfaces with tunable adhesion based on hydrophobic silica nanoparticle aggregates. Colloid and Polymer Science 293(10): 2815-2821.

96. Hwang J, Ahn Y (2015) Fabrication of Superhydrophobic Silica Nanoparticles and Nanocomposite Coating on Glass Surfaces. Bulletin of the Korean Chemical Society 36(1): 391-394.

97. Tao C, Yan H, Yuan X, Yao C, Yin Q, et al. (2016) Synthesis of shape-controlled hollow silica nanostructures with a simple soft-templating method and their application as superhydrophobic antireflective coatings with ultralow refractive indices. Colloids and Surfaces A: Physicochemical and Engineering Aspects 501: 17-23.

98. Tao C, Yan H, Yuan X, Yin Q, Zhu J, et al. (2016) Sol-gel based antireflective coatings with superhydrophobicity and exceptionally low refractive indices built from trimethylsilanized hollow silica nanoparticles. Colloids and Surfaces A: Physicochemical and Engineering Aspects 509: 307313.

99. Tao C, Yan H, Yuan X, Yin Q, Zhu J, et al. (2016) Detailed analysis and formation mechanism of superhydrophobic antireflective coatings with adjustable refractive index from trimethylsilanized silica nanoparticles. Journal of Sol-Gel Science and Technology 80(1): 10-18.

100. Membreno D, Smith L, Dunn B (2014) Silica sol-gel chemistry: creating materials and architectures for energy generation and storage. Journal of sol-gel science and technology 70(2): 203-215.

101. Gurav AB, Xu Q Latthe SS, Vhatkar RS, Liu S, et al. (2015) Superhydrophobic coatings prepared from methyl-modified silica particles using simple dipcoating method. Ceramics International 41(2B): 3017-3023.

102. Zhang W, Xiang T, Liu F, Zhang M, Gan W, et al. (2017) Facile Design and Fabrication of Superwetting Surfaces with Excellent Wear-Resistance. ACS applied materials \& interfaces 9(18): 15776-15784.
103. Zhang X, Si Y, Mo J, Guo Z (2017) Robust micronanoscale flowerlike $\mathrm{ZnO} /$ epoxy resin superhydrophobic coating with rapid healing ability. Chemical Engineering Journal 313: 1152-1159.

104. Psarski M, Celichowski G, Marczak J, Gumowski K, Sobieraj GB, et al. (2013) Superhydrophobic dualsized filler epoxy composite coatings. Surface and Coatings Technology 225: 66-74.

105. Martin S, Bhushan B (2017) Transparent, wearresistant, superhydrophobic and superoleophobic poly (dimethylsiloxane)(PDMS) surfaces. Journal of colloid and interface science 488: 118-126.

106. Wang Z, Zhu H, Cao N, Du R, Liu Y, et al. (2017) Superhydrophobic surfaces with excellent abrasion resistance based on benzoxazine/mesoporous $\mathrm{SiO}_{2}$. Materials Letters 186: 274-278.

107. Ye H, Zhu L, Li W, Liu H, Chen H (2016) Constructing fluorine-free and cost-effective superhydrophobic surface with normal-alcohol-modified hydrophobic $\mathrm{SiO}_{2}$ nanoparticles. ACS applied materials \& interfaces 9(1): 858-867.

108. Lu Y, Sathasivam S, Song J, Crick CR, Carmalt CJ, et al. (2015) Robust self-cleaning surfaces that function when exposed to either air or oil. Science 347(6226): 1132-1135.

109. Loy DA, Mather B, Straumanis AR, Baugher C, Schneider DA, et al. (2004) Effect of $\mathrm{pH}$ on the gelation time of hexylene-bridged polysilsesquioxanes. Chemistry of materials 16(11): 2041-2043.

110. Pilotek S, Schmidt HK (2003) Wettability of microstructured hydrophobic sol-gel coatings. Journal of sol-gel science and technology 26(1-3): 789-792.

111. Cui Z, Yin L, Wang Q Ding J, Chen Q (2009) A facile dip-coating process for preparing highly durable superhydrophobic surface with multi-scale structures on paint films. J Colloid Interface Sci 337(2): 531-537.

112. Yang T, Tian H, Chen Y (2009) Preparation of superhydrophobic silica films with honeycomb-like structure by emulsion method. Journal of sol-gel science and technology 49(2): 243-246.

113. Qu A, Wen X, Pi P, Cheng J, Yang Z (2008) Morphologies and superhydrophobicity of hybrid film 


\section{Petroleum \& Petrochemical Engineering Journal}

surfaces based on silica and fluoropolymer. Journal of materials science \& technology 24(5): 693-699.

114. Wenzel RN (1936) Resistance of solid surfaces to wetting by water. Industrial \& Engineering Chemistry 28(8): 988-994.

115. Cassie A, Baxter S (1944) Wettability of porous surfaces. Transactions of the Faraday society 40: 546551.

116. Marmur A (2003) Wetting on hydrophobic rough surfaces: to be heterogeneous or not to be? Langmuir 19(20): 8343-8348.

117. Whyman G, Bormashenko E, Stein T (2008) The rigorous derivation of Young, Cassie-Baxter and Wenzel equations and the analysis of the contact angle hysteresis phenomenon. Chemical Physics Letters 450(4-6): 355-359.

118. Ishino C, Okumura K (2008) Wetting transitions on textured hydrophilic surfaces. The European Physical Journal E 25(4): 415-424.

119. Fang J, Wang H, Xue Y, Wang X, Lin T (2010) Magnetinduced temporary superhydrophobic coatings from one-pot synthesized hydrophobic magnetic nanoparticles. ACS applied materials \& interfaces 2(5): 1449-1455.

120. Chevallier P, Turgeon S, Sarra-Bournet C, Turcotte R, Laroche G (2011) Characterization of multilayer antifog coatings. ACS applied materials \& interfaces 3(3): 750-758.

121. Zou X, Tao C, Yang K, Yang F, Lv H, et al. (2018) Rational design and fabrication of highly transparent, flexible, and thermally stable superhydrophobic coatings from raspberry-like hollow silica nanoparticles. Applied Surface Science 440: 700-711.

122. Tao C, Zou X, Reddy KM, Zhang L, Jiang B (2019) A hydrophobic ultralow refractive-index silica coating towards double-layer broadband antireflective coating with exceptionally high vacuum stability and laser-induced damage threshold. Colloids and Surfaces A: Physicochemical and Engineering Aspects 563: 340-349.

123. Tao C, Yang K, Zou X, Yan H, Yuan X, et al. (2018) Double-layer tri-wavelength hydrophobic antireflective coatings derived from methylated silica nanoparticles and hybrid silica nanoparticles. Journal of Sol-Gel Science and Technology 86(2): 285-292.

124. Hikita M, Tanaka K, Nakamura T, Kajiyama T, Takahara A (2005) Super-liquid-repellent surfaces prepared by colloidal silica nanoparticles covered with fluoroalkyl groups. Langmuir 21(16): 72997302.

125. Duparré A, Flemming M, Steinert J, Reihs K (2002) Optical coatings with enhanced roughness for ultrahydrophobic, low-scatter applications. Applied optics 41(16): 3294-3298.

126. Guo Z, Liu W, Su BL (2011) Superhydrophobic surfaces: from natural to biomimetic to functional. Journal of colloid and interface science 353(2): 335355.

127. Lai YK, Chen Z, Lin C-J (2011) Recent progress on the superhydrophobic surfaces with special adhesion: from natural to biomimetic to functional. Journal of Nanoengineering and Nanomanufacturing 1(1): 1834.

128. Latthe SS, Gurav AB, Maruti CS, Vhatkar RS (2012) Recent progress in preparation of superhydrophobic surfaces: a review. Journal of Surface Engineered Materials and Advanced Technology 2(2): 76.

129. Zhang Y-L, Xia H, Kim E, Sun H-B (2012) Recent developments in superhydrophobic surfaces with unique structural and functional properties. Soft Matter 8(44): 11217-11231.

130. Celia E, Darmanin T, de Givenchy ET, Amigoni S, Guittard F (2013) Recent advances in designing superhydrophobic surfaces. Journal of colloid and interface science 402: 1-18.

131. Birjandi FC, Sargolzaei J (2014) Super-non-wettable surfaces: a review. Colloids and Surfaces A: Physicochemical and Engineering Aspects 448: 93106.

132. Söz CK, Yilgör E, Yilgör I (2015) Influence of the average surface roughness on the formation of superhydrophobic polymer surfaces through spincoating with hydrophobic fumed silica. Polymer 62 : 118-128.

133. Latthe SS, Terashima C, Nakata K, Sakai M, Fujishima A (2014) Development of sol-gel processed semi- 


\section{Petroleum \& Petrochemical Engineering Journal}

transparent and self-cleaning superhydrophobic coatings. Journal of Materials Chemistry A 2(15): 5548-5553.

134. Rao AV, Latthe SS, Nadargi DY, Hirashima H, Ganesan V (2009) Preparation of MTMS based transparent superhydrophobic silica films by sol-gel method. Journal of colloid and interface science 332(2): 484490.

135. Yildirim A, Khudiyev T, Daglar B, Budunoglu H, Okyay AK (2013) Superhydrophobic and omnidirectional antireflective surfaces from nanostructured ormosil colloids. ACS applied materials \& interfaces 5(3): 853-860.

136. Wang N, Xiong D (2014) Influence of trimethylethoxysilane on the wetting behavior, humidity resistance and transparency of tetraethylorthosilicate based films. Applied Surface Science 292: 68-73.

137. Cai S, Zhang Y, Zhang H, Yan H, Lv H, et al. (2014) Sol-gel preparation of hydrophobic silica antireflective coatings with low refractive index by base/acid two-step catalysis. ACS applied materials \& interfaces 6(14): 11470-11475.

138. Wang N, Xiong D (2014) Comparison of micro/nano-hierarchical and nano-scale roughness of silica membranes in terms of wetting behavior and transparency. Colloids and Surfaces A: Physicochemical and Engineering Aspects 446: 8-14.

139. Meng X, Wang Y, Wang H, Zhong J, Chen R (2014) Preparation of hydrophobic and abrasion-resistant silica antireflective coatings by using a cationic surfactant to regulate surface morphologies. Solar Energy 101: 283-290.

140. Gurav AB, Xu Q, Latthe SS, Vhatkar R, Liu S, et al. (2015) Superhydrophobic coatings prepared from methyl-modified silica particles using simple dipcoating method. Ceramics International 41(2): $3017-$ 3023.

141. Purcar V, Donescu D, Spataru IC, Ghiurea M, Caprarescu S, et al. (2013) Surface modification of solgel hybrid films using fluorinated silica nanoparticles. Revue Roumanie de Chimie 58(1): $37-$ 42.
142. Spataru C, Purcar V, Ghiurea M, Somoghi R, Donescu D (2013) Superhydrophobic surfaces obtained from bilayer hybrids and silica nanoparticles. Journal of Optoelectronics And Advanced Materials 15(11-12): 1438-1444.

143. An Q, Xu W, Hao L, Fu Y, Huang L (2013) Fabrication of superhydrophobic fabric coating using microphase-separated dodecafluoroheptyl-containing polyacrylate and nanosilica. Journal of Applied Polymer Science 128(5): 3050-3056.

144. Aytug T, Lupini AR, Jellison GE, Joshi PC, Ivanov IH, et al. (2015) Monolithic graded-refractive-index glass-based antireflective coatings: broadband/omnidirectional light harvesting and selfcleaning characteristics. Journal of Materials Chemistry C 3(21): 5440-5449.

145. Barkhudarov PM, Shah PB, Watkins EB, Doshi DA, Brinker CJ, et al. (2008) Corrosion inhibition using superhydrophobic films. Corrosion Science 50(3): 897-902.

146. Bravo J, Zhai L, Wu Z, Cohen RE, Rubner MF (2007) Transparent superhydrophobic films based on silica nanoparticles. Langmuir 23(13): 7293-7298.

147. Budunoglu H, Yildirim A, Guler MO, Bayindir M (2011) Highly transparent, flexible, and thermally stable superhydrophobic ORMOSIL aerogel thin films. ACS applied materials \& interfaces 3(2): 539-545.

148. Caldona EB, De Leon ACC, Thomas PG, Naylor III DF (2017) Pajarito BB, Advincula RC. Superhydrophobic Rubber-Modified Polybenzoxazine/SiO2 Nanocomposite Coating with Anticorrosion, Anti-Ice, and Superoleophilicity Properties. Industrial \& Engineering Chemistry Research 56(6): 1485-1497.

149. Cholewinski A, Trinidad J, McDonald B, Zhao B (2014) Bio-inspired polydimethylsiloxanefunctionalized silica particles-epoxy bilayer as a robust superhydrophobic surface coating. Surface and Coatings Technology 254: 230-237.

150. Ding X, Zhou S, Gu G, Wu L (2011) A facile and largearea fabrication method of superhydrophobic selfcleaning fluorinated polysiloxane $/ \mathrm{TiO}_{2}$ nanocomposite coatings with long-term durability. Journal of Materials Chemistry 21(17): 6161-6164. 


\section{Petroleum \& Petrochemical Engineering Journal}

151. Ebert D, Bhushan B (2012) Transparent, superhydrophobic, and wear-resistant coatings on glass and polymer substrates using $\mathrm{SiO} 2, \mathrm{ZnO}$, and ITO nanoparticles. Langmuir 28(31): 11391-11399.

152. Gao L, McCarthy TJ (2006) A perfectly hydrophobic surface $(\theta A / \theta R=180 / 180)$. Journal of the American Chemical Society 128(28): 9052-9053.

153. Hsieh CT, Chang BS, Lin JY (2011) Improvement of water and oil repellency on wood substrates by using fluorinated silica nanocoating. Applied Surface Science 257(18): 7997-8002.

154. Huang WH, Lin CS (2014) Robust superhydrophobic transparent coatings fabricated by a low-temperature sol-gel process. Applied Surface Science 305: 702709.

155. Huang L, Chen K, Lin C, Yang R, Gerhardt RA (2011) Fabrication and characterization of superhydrophobic high opacity paper with titanium dioxide nanoparticles. Journal of Materials Science 46(8): 2600-2605.

156. Huang Y, Hu M, Yi S, Liu X, Li H, Huang C, et al. (2012) Preparation and characterization of silica/fluorinated acrylate copolymers hybrid films and the investigation of their icephobicity. Thin Solid Films 520(17): 5644-5651.

157. Jiang T, Guo Z (2016) Robust superhydrophobic tungsten oxide coatings with photochromism and UV durability properties. Applied Surface Science 387: 412-418.

158. Kamitani K, Teranishi T (2003) Development of water-repellent glass improved water-sliding property and durability. Journal of sol-gel science and technology 26(1-3): 823-825.

159. Shateri-Khalilabad M, Yazdanshenas ME (2013) Preparation of superhydrophobic electroconductive graphene-coated cotton cellulose. Cellulose 20(2): 963-972.

160. Khoo HS, Tseng FG (2008) Engineering the 3D architecture and hydrophobicity of methyltrichlorosilane nanostructures. Nanotechnology 19(34): 345603.

161. Kumar D, Wu X, Fu Q, Ho JWC, Kanhere PD, et al. (2015) Development of durable self-cleaning coatings using organic-inorganic hybrid sol-gel method. Applied surface science 344: 205-212.

162. Lakshmi R, Bera P, Anandan C, Basu BJ (2014) Effect of the size of silica nanoparticles on wettability and surface chemistry of sol-gel superhydrophobic and oleophobic nanocomposite coatings. Applied Surface Science 320(C): 780-786.

163. Li X, Shen J (2011) A facile two-step dipping process based on two silica systems for a superhydrophobic surface. Chemical Communications 47(38): 1076110763

164. Li H, Zhao Y, Yuan X (2013) Facile preparation of superhydrophobic coating by spraying a fluorinated acrylic random copolymer micelle solution. Soft Matter 9(4): 1005-1009.

165. Liang J, Hu Y, Wu Y, Chen $\mathrm{H}$ (2014) Facile formation of superhydrophobic silica-based surface on aluminum substrate with tetraethylorthosilicate and vinyltriethoxysilane as co-precursor and its corrosion resistant performance in corrosive $\mathrm{NaCl}$ aqueous solution. Surface and Coatings Technology 240: 145153.

166. Yang CC, Li YJ, Liou TH (2011) Preparation of novel poly (vinyl alcohol)/SiO2 nanocomposite membranes by a sol-gel process and their application on alkaline DMFCs. Desalination 276(1-3): 366-372.

167. Liu M, Qing Y, Wu Y, Liang J, Luo S (2015) Facile fabrication of superhydrophobic surfaces on wood substrates via a one-step hydrothermal process. Applied Surface Science 330: 332-338.

168. Liu X, Wang Y, Chen Z, Ben K, Guan Z (2016) A selfmodification approach toward transparent superhydrophobic glass for rainproofing and superhydrophobic fiberglass mesh for oil water separation. Applied Surface Science 360: 789-797.

169. Luo G, Jin Z, Dong Y, Huang J, Zhang R, et al. (2018) Preparation and performance enhancements of wearresistant, transparent $\mathrm{PU} / \mathrm{SiO} 2$ superhydrophobic coating. Surface Engineering 34(2): 139-145.

170. Ogihara H, Xie J, Saji T (2015) Controlling surface energy of glass substrates to prepare superhydrophobic and transparent films from silica nanoparticle suspensions. Journal of colloid and interface science 437: 24-27. 


\section{Petroleum \& Petrochemical Engineering Journal}

171. Prakash SS, Brinker CJ, Hurd AJ, Rao SM (1995) Silica aerogel films prepared at ambient pressure by using surface derivatization to induce reversible drying shrinkage. Nature 374(6521): 439-443.

172. Prasad G, Chakradhar R, Bera P, Prabu AA, Anandan $C$ (2017) Transparent hydrophobic and superhydrophobic coatings fabricated using polyamide $12-\mathrm{SiO}_{2}$ nanocomposite. Surface and Interface Analysis 49(5): 427-433.

173. Ramezani M, Vaezi MR, Kazemzadeh A (2014) Preparation of silane-functionalized silica films via two-step dip coating sol-gel and evaluation of their superhydrophobic properties. Applied Surface Science 317: 147-153.

174. Latthe SS, Imai H, Ganesan V, Rao AV (2010) Porous superhydrophobic silica films by sol-gel process. Microporous and Mesoporous Materials 130(1-3): 115-121.

175. Shang Q, Zhou Y, Xiao G (2014) A simple method for the fabrication of silica-based superhydrophobic surfaces. Journal of Coatings Technology and Research 11(4): 509-515.

176. Shang H, Wang Y, Limmer S, Chou T, Takahashi K, et al. (2005) Optically transparent superhydrophobic silica-based films. Thin Solid Films 472(1-2): 37-43.

177. Shi Y, Xiao X (2016) Facile spray-coating for fabrication of superhydrophobic Si02/PVDF nanocomposite coating on paper surface. Journal of Dispersion Science and Technology 37(5): 640-645.

178. Shirgholami MA, Shateri-Khalilabad M, Yazdanshenas ME (2013) Effect of reaction duration in the formation of superhydrophobic polymethylsilsesquioxane nanostructures on cotton fabric. Textile Research Journal 83(1): 100-110.

179. Song W, Lima AC, Mano JF (2010) Bioinspired methodology to fabricate hydrogel spheres for multiapplications using superhydrophobic substrates. Soft Matter 6(23): 5868-5871.

180. Su C, Li J, Geng H, Wang Q Chen Q (2006) Fabrication of an optically transparent superhydrophobic surface via embedding nano-silica. Applied Surface Science 253(5): 2633-2636.
181. Gu G, Dang H, Zhang Z, Wu Z (2006) Fabrication and characterization of transparent superhydrophobic thin films based on silica nanoparticles. Applied physics A 83(1): 131-132.

182. Sun Q, Lu Y, Liu Y (2011) Growth of hydrophobic TiO2 on wood surface using a hydrothermal method. Journal of Materials Science 46(24): 7706-7712.

183. Tang X, Nan S, Wang T, Chen Y, Yu F, et al. (2013) Facile strategy for fabrication of transparent superhydrophobic coatings on the surface of paper. RSC Advances 3(36): 15571-15575.

184. Tu K, Wang X, Kong L, Guan H (2018) Facile preparation of mechanically durable, self-healing and multifunctional superhydrophobic surfaces on solid wood. Materials \& Design 140: 30-36.

185. Wang N, Xiong D (2014) Superhydrophobic membranes on metal substrate and their corrosion protection in different corrosive media. Applied Surface Science 305: 603-608.

186. Wang S, Liu C, Liu G, Zhang M, Li J, et al. (2011) Fabrication of superhydrophobic wood surface by a sol-gel process. Applied Surface Science 258(2): 806810.

187. Wang C, Piao C, Lucas C (2011) Synthesis and characterization of superhydrophobic wood surfaces. Journal of Applied Polymer Science 119(3): 16671672.

188. Wang S, Yu X, Zhang Y (2017) Large-scale fabrication of translucent, stretchable and durable superhydrophobic composite films. Journal of Materials Chemistry A 5(45): 23489-23496.

189. Wei HS, Kuo CC, Jaing CC, Chang YC, Lee CC (2014) Highly transparent superhydrophobic thin film with low refractive index prepared by one-step coating of modified silica nanoparticles. Journal of sol-gel science and technology 71(1): 168-175.

190. Wu LY, Soutar A, Zeng X (2005) Increasing hydrophobicity of sol-gel hard coatings by chemical and morphological modifications. Surface and Coatings Technology 198(1-3): 420-424.

191. Wu LY, Tan G, Zeng X, Li T, Chen Z (2006) Synthesis and characterization of transparent hydrophobic sol- 


\section{Petroleum \& Petrochemical Engineering Journal}

gel hard coatings. Journal of sol-gel science and technology 38(1): 85-89.

192. Wu Y, Jia S, Wang S, Qing Y, Yan N, et al. (2017) A facile and novel emulsion for efficient and convenient fabrication of durable superhydrophobic materials. Chemical Engineering Journal 328: 186-196.

193. Xu L, Geng Z, He J, Zhou G (2014) Mechanically robust, thermally stable, broadband antireflective, and superhydrophobic thin films on glass substrates. ACS applied materials \& interfaces 6(12): 9029-9035.

194. Xue CH, Guo XJ, Zhang MM, Ma JZ, Jia ST, et al. (2015) Fabrication of robust superhydrophobic surfaces by modification of chemically roughened fibers via thiolene click chemistry. Journal of Materials Chemistry A 3(43): 21797-21804.

195. Yang H, Deng Y (2008) Preparation and physical properties of superhydrophobic papers. Journal of Colloid and Interface Science 325(2): 588-593.

196. Zhang L, Zhang X, Dai Z, Wu J, Zhao N, et al. (2010) Micro-nano hierarchically structured nylon 6, 6 surfaces with unique wettability. J Colloid Interface Sci 345(1): 116-119.

197. Zhang J, Seeger S (2011) Superhyrophobic Materials: Polyester Materials with Superwetting Silicone Nanofilaments for Oil/Water Separation and Selective Oil Absorption. Advanced Functional Materials 21(24): 4632.

198. Zhang X, Lan P, Lu Y, Li J, Xu H, et al. (2014) Multifunctional antireflection coatings based on novel hollow silica-silica nanocomposites. ACS Appl Mater Interfaces 6(3): 1415-1423.

199. Zhao L, Xu W, Liu J, Liu W, Yao J, et al. (2014) Superhydrophobic surface fabricated by modifying silica coated multiwalled carbon nanotubes composites. Journal of sol-gel science and technology 69(1): 107-113.

200. Zhao Y, Xu Z, Wang X, Lin T (2012) Photoreactive azido-containing silica nanoparticle/polycation multilayers: durable superhydrophobic coating on cotton fabrics. Langmuir 28(15): 6328-6335.

201. Zhong M, Zhang Y, Li X, Wu X (2018) Facile fabrication of durable superhydrophobic silica/epoxy resin coatings with compatible transparency and stability. Surface and Coatings Technology 347: 191198.

202. Zhou H, Wang H, Niu H, Gestos A, Wang $X$, et al. (2012) Fluoroalkyl silane modified silicone rubber/nanoparticle composite: a super durable, robust superhydrophobic fabric coating. Advanced materials 24(18): 2409-2412.

203. Zhou W, Li G, Wang L, Chen Z, Lin Y (2017) A facile method for the fabrication of a superhydrophobic polydopamine-coated copper foam for oil/water separation. Applied Surface Science 413: 140-148.

204. Wang B, Liu Y, Zhang Y, Guo Z, Zhang H, et al. (2015) Bioinspired superhydrophobic Fe304@ polydopamine@Ag hybrid nanoparticles for liquid marble and oil spill. Advanced Materials Interfaces 2(13). 